\title{
Enhancement of properties of PA6/PP nanocomposites via organic modification and compatibilization
}

\author{
Kusmono ${ }^{1}$, Z. A. Mohd Ishak ${ }^{*}$, W. S. Chow ${ }^{1}$, T. Takeichi², Rochmadi ${ }^{3}$ \\ ${ }^{1}$ School of Materials and Mineral Resources Engineering, Engineering Campus, Universiti Sains Malaysia, \\ 14300 Nibong Tebal, Pulau Pinang, Malaysia \\ 2Department of Materials Science, Toyohashi University of Technology, Toyohashi 441-8580, Japan \\ ${ }^{3}$ Department of Chemical Engineering, Gadjah Mada University, Jln. Grafika 2 Yogyakarta, Indonesia
}

Received 12 May 2008; accepted in revised form 6 August 2008

\begin{abstract}
Nanocomposites based on polyamide 6/polypropylene (PA6/PP = 70/30) blend containing organophilic montmorillonite (OMMT) and maleated polypropylene (PP-g-MA) as compatibilizer were prepared by melt compounding followed by injection molding. Modification of montmorillonite (MMT) with dodecyalmine was successfully performed. The morphological and mechanical properties of nanocomposites were investigated by using X-ray diffraction (XRD), transmission electron microscopy (TEM), tensile, flexural, and impact tests. The thermal stability of nanocomposites was characterized by using thermogravimetric analysis (TGA) and heat distortion temperature (HDT). XRD and TEM results indicated that the intercalated structure was obtained for PA6/PP/MMT composite, a mixture of intercalated and exfoliated structures for PA6/PP/OMMT nanocomposite, and exfoliated structure for PP-g-MA compatibilized PA6/PP/OMMT nancomposite. Thermal stability and HDT of PA6/PP matrix were improved by the addition of both MMT and OMMT. The introduction of PP-g-MA into the PA6/PP/OMMT nanocomposite enhanced the properties such as stiffness, strength, ductility, impact strength, and HDT. This was attributed to the compatibilizing effect of PP-g-MA which improved interfacial adhesion between OMMT with PA6/PP matrix and also promoted the degree of exfoliation of silicate layers in the PA6/PP matrix.
\end{abstract}

Keywords: nanocomposites, polyamide 6, polypropylene, OMMT, PP-g-MA

\section{Introduction}

Blends of polyamide 6 (PA6) and polypropylene (PP) have received much attention over recent years, since they combine thermomechanical characteristics of the former with the ease of processing of the latter. Unfortunately, these polymers are incompatible because of their different polarity and crystalline morphologies [1]. Therefore, compatibilizing agent has to be used to reduce the interfacial tension and to improve the adhesion between two constituents. Maleated PP (PP-g-MA) has well been documented as one of the most effectively compatibilizing agents for PA6/PP blends [2, 3].
Compounding polymers with inorganic materials has long been an interesting topic of scientific research and industrial applications, because inorganic materials can be employed to improve the mechanical properties, provide enhanced barrier properties and reduce the flammability of the resultant polymer composites [4]. Among various inorganic fillers, montmorillonite clay with large aspect ratios has proven to be particularly effective in polymer matrix reinforcement [5]. However, pristine MMT layers are not easily exfoliated in most polymers due to the strong electrostatic forces between them and to the chemical incompatibility 
Table 1. Designation and composition of samples

\begin{tabular}{|l|l|c|}
\hline \multicolumn{1}{|c|}{ Sample designation } & \multicolumn{1}{|c|}{ Composition } & Parts [phr] \\
\hline PA6/PP & PA6/PP & $70 / 30$ \\
\hline PA6/PP/PP-g-MA & PA6/PP/PP-g-MA & $70 / 30 / 5$ \\
\hline PA6/PP/MMT & PA6/PP/MMT & $70 / 30 / 4$ \\
\hline PA6/PP/OMMT & PA6/PP/Dodecylamine modified MMT & $70 / 30 / 4$ \\
\hline PA6/PP/OMMT/PP-g-MA & PA6/PP/Dodecylamine modified MMT/PP-g-MA & $70 / 30 / 4 / 5$ \\
\hline
\end{tabular}

of the MMT surface with polymers. Long-chain alkyl ammonium surfactants were usually employed to pre-modify the MMT interlayer galleries through cation exchange reactions so as to weaken the interaction between adjacent layers and to enhance the compatibility/wettability of the MMT layer with the polymer matrix [6]. Dodecylamine is one of most popular alkyl ammonium surfactants and has been widely employed for preparation of polymer nanocomposites. The dodecylamine modified MMT improved the mechanical properties for nanocomposites based on PA6 [7] and PP [8]. Recently, nanocomposites based on PA6/PP blends have been extensively studied by many researchers $[9,10]$. Most of them prepared PA6/PP nanocomposites using a commercial organoclay. To our knowledge, the application of organic modification of MMT such as the dodecylamine modified MMT for PA6/PP nanocomposites was still limited.

In this work, nanocomposites based on PA6/PP blends $(\mathrm{PA} 6 / \mathrm{PP}=70 / 30)$ were prepared by melt compounding using a co-rotating twin screw extruder followed by injection molding. The dodecylamine modified montmorillonite and PP-g-MA were used as reinforcement and compatibilizer, respectively. The influence of organic modification and compatibilizer on the morphological and mechanical properties of PA6/PP/OMMT nanocomposites was investigated by using $\mathrm{X}$-ray diffraction (XRD), transmission electron microscopy (TEM), tensile, flexural, and impact tests. In addition, thermal stability was also characterized by thermogravimetric analysis (TGA) and heat distortion temperature tests.

\section{Experimental}

\subsection{Materials}

PA6 (Amilan CM 1017) used in this study was a commercial product of Toray Nylon Resin AMILAN, Japan. The melt flow index or MFI (at $230^{\circ} \mathrm{C}$ and $2.16 \mathrm{~kg}$ load) and density of PA6 were $35 \mathrm{~g} / 10 \mathrm{~min}$ and $1.14 \mathrm{~g} / \mathrm{cm}^{3}$, respectively. PP (ProFax SM-240) was purchased from Titan Himont Polymer (M) Sdn. Bhd., Malaysia. The MFI (at $230^{\circ} \mathrm{C}$ and $2.16 \mathrm{~kg}$ load) and density of PP were $25 \mathrm{~g} / 10 \mathrm{~min}$ and $0.9 \mathrm{~g} / \mathrm{cm}^{3}$, respectively. Polypropylene grafted with $1.2 \mathrm{wt} \%$ of maleic anhydride (Polybond 3200) was purchased from Uniroyal Chemical, Middlebury. Kunipia-F, sodium montmorillonite (MMT) clay with cation exchange capacity (CEC) of $119 \mathrm{meq} / 100 \mathrm{~g}$, was supplied by Kunimine Industry Co., Japan. The alkyl ammonium salt used to modify Na-MMT clay was dodecylamine $\left[\mathrm{CH}_{3}\left(\mathrm{CH}_{2}\right)_{11} \mathrm{NH}_{2}\right]$, supplied from Kishida Chemical Co., Osaka Japan. The designation and composition of samples tested are given in Table 1.

\subsection{Preparation of OMMT}

Organophilic montmorillonite (OMMT) was prepared by cation exchange of MMT with dodecylamine according to a method reported by Agag and Takeichi [11]. Dodecyl ammonium chloride solution was prepared by the addition of $4.17 \mathrm{~g}$ of conc. $\mathrm{HCl}(40 \mathrm{mmol})$ to $7.41 \mathrm{~g}$ of dodecylamine (40 mmol) in $1000 \mathrm{ml}$ of distilled water. The mixture was stirred at $80^{\circ} \mathrm{C}$ until a clear solution was obtained, indicating the formation of dodecyl ammonium chloride. To this solution, a suspension of $20 \mathrm{~g}$ of MMT in $1000 \mathrm{ml}$ of distilled water was added; the mixture was mechanically stirred at $80^{\circ} \mathrm{C}$ for 5 hours. The obtained white precipitate was collected by suction filtration and then washed by hot water to remove salt. This process was repeated several times until no chloride was detected in the filtrate by $0.1 \mathrm{~N} \mathrm{AgNO}_{3}$. The resultant precipitate was air-dried, ground in mortar, sieved to obtain powders, and finally dried in an air-blowing oven at $110^{\circ} \mathrm{C}$ for 3 days, affording white powder. The modified MMT was termed OMMT. 


\subsection{Sample preparation}

PA6/PP/OMMT nanocomposites were prepared in a co-rotating intermeshing twin-screw extruder (BERSTORFF ZE 25, Germany) at temperature ranging from 230 to $240^{\circ} \mathrm{C}$ and at a screw speed of $70 \mathrm{rpm}$. The extrudates were then injection-molded into standard tensile (ASTM D638 type I) and flexural specimens (ASTM D790) using an injection molding machine (Haitian HTF160X, China). The barrel zone temperatures were set at 190, 235, 250, 255,260 , and $250^{\circ} \mathrm{C}$ and a mold temperature of $110^{\circ} \mathrm{C}$. Prior to extrusion and injection molding, all pellets and clay were dried in an oven at $80^{\circ} \mathrm{C}$ for 15 hours.

\subsection{Characterization and mechanical testing}

Fourier transform infra-red spectroscopy (FT-IR) analysis of MMT and OMMT were performed on JASCO spectrophotometer model FT/IR-420, Japan. About $2 \mathrm{mg}$ of sample was mixed with $200 \mathrm{mg}$ of potassium bromide $(\mathrm{KBr})$ prior to compacting into thin pellets with a hydraulic press. FTIR spectra were obtained from $\mathrm{KBr}$ pellets at wave numbers from $400-4000 \mathrm{~cm}^{-1}$. X-ray diffraction measurements were conducted directly from MMT and OMMT powders while for the nanocomposites were carried out on bars. All these experiments were performed in reflection mode with a D5000 diffractometer (Siemens, Germany) using $\mathrm{CuK}_{\alpha}$ radiation at a scan rate of $0.3 \% \mathrm{~min}$ in a $2 \theta$ range of $2-10^{\circ}$, and operated at $30 \mathrm{kV}$ and $20 \mathrm{~mA}$. TEM measurements were carried out with a JEOL JEM200CX TEM (Japan) operating at an accelerating voltage of $200 \mathrm{kV}$. The specimens were prepared using a Leica Ultracut UCT ultramicrotome. Ultrathin sections of about $60 \mathrm{~nm}$ in thickness were cut with a Diatome diamond knife $\left(35^{\circ}\right)$ at room temperature.

The thermal stability of samples was studied using thermogravimetric analysis (TGA; Perkin-Elmer TGA-6, USA). The sample was heated from room temperature to $600^{\circ} \mathrm{C}$ at $10^{\circ} \mathrm{C} / \mathrm{min}$ under nitrogen atmosphere. Heat distortion temperature (HDT) of samples was measured using specimens having dimensions $125 \times 12.50 \times 3.0 \mathrm{~mm}^{3}$ according to ASTM D 648. The test was conducted at a heating rate of $2^{\circ} \mathrm{C} / \mathrm{min}$ and a fiber stress of $1.8 \mathrm{MPa}$ using a 4 Station Advanced HDT/Vicat Softening Point Apparatus (Ray-Ryan Test Equipment Ltd, UK). Tensile and flexural tests were performed on a universal testing machine (Instron 3366, USA) at room temperature according to ASTM D638 type I and ASTM D790, respectively. Tensile test was conducted at a crosshead speed of $50 \mathrm{~mm} / \mathrm{min}$. For flexural test, a three-point bending configuration was selected with a support span length of $50 \mathrm{~mm}$ and a crosshead speed of $3 \mathrm{~mm} / \mathrm{min}$. Izod impact test was carried out on notched specimens using a Pendulum Hammer Impact 25 S/N V67R (Galdabini, Italy) according to ASTM 256-02 with a impact speed of $3.46 \mathrm{~m} / \mathrm{s}$.

\section{Results and discussion}

\subsection{FT-IR analysis}

Figure 1 shows the FT-IR spectra of MMT and OMMT. The absorption peaks at 3629, 1643, 1043, 914 , and $521 \mathrm{~cm}^{-1}$ correspond to $-\mathrm{OH}$ stretching, $-\mathrm{OH}$ bending, $\mathrm{Si}-\mathrm{O}$ stretching, $-\mathrm{OH}$ bending, and $\mathrm{Si}-\mathrm{O}$ bending, respectively, which are characteristic absorption bands of MMT. In addition to those peaks, OMMT also exhibits peaks at 3251 and $2920 \mathrm{~cm}^{-1}$ corresponding to $\mathrm{N}-\mathrm{H}$ stretching and $-\mathrm{CH}_{3}$ stretching, respectively, while peaks at both 2850 and 1469 corresponds to $-\mathrm{CH}_{2}$ stretching. This indicates that dodecylammoniun has been intercalated into the galleries of MMT by a cation exchange reaction.

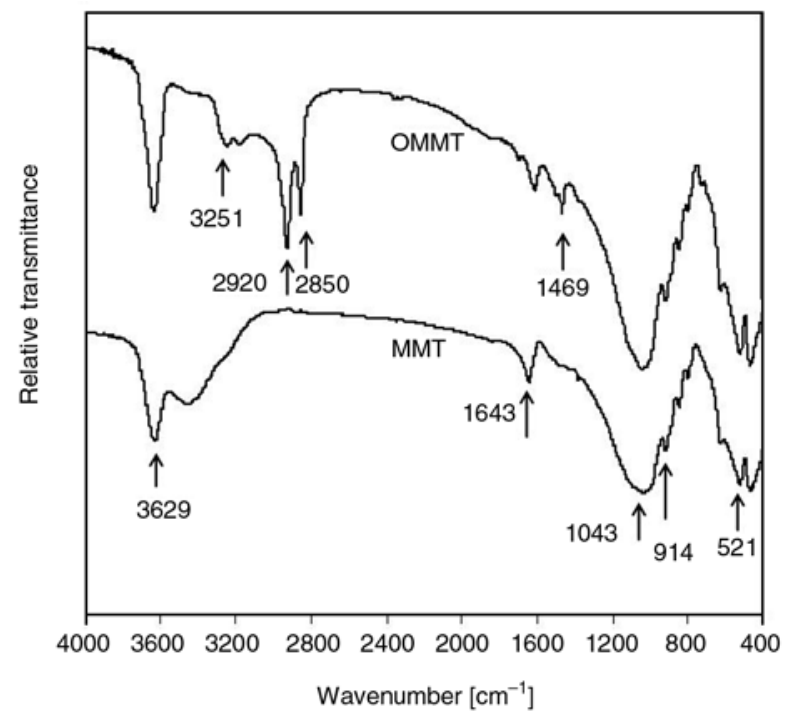

Figure 1. FT-IR spectra of MMT and OMMT 


\subsection{XRD}

Figure 2 presents the XRD patterns of MMT and OMMT. MMT and OMMT depict the characteristic diffraction peaks at $2 \theta=7.12$ and $5.44^{\circ}$ corresponding to basal spacing $\left(d_{001}\right)$ of 1.24 and $1.62 \mathrm{~nm}$, respectively. Thus, OMMT exhibits a larger basal spacing than MMT. The expanded basal spacing suggests that the dodecylammonium has intercalated into the galleries of MMT, which is in agreement with the FT-IR results discussed earlier. The increase in basal spacing also indicates the successful modification of MMT through a cation exchange reaction.

Figure 3 shows the XRD patterns of PA6/PP blends and its nanocomposites. After incorporating of the MMT into PA6/PP matrix by melt compounding, the diffraction peak of MMT shifts to $2 \theta=6.29^{\circ}$, with a basal spacing of $1.40 \mathrm{~nm}$, indicating a slight increase in basal spacing. This suggests the polymer molecular chains have entered into the galleries of MMT and the intercalated structure is formed in the PA6/PP/MMT composite. In the XRD pattern of PA6/PP/OMMT nanocomposite, a broad shoulder peak appears at $2 \theta=2.99^{\circ}$ corresponding to a basal spacing of $2.95 \mathrm{~nm}$. The presence of a broad shoulder peak probably indicates the formation of a mixture of intercalated and exfoliated structures in the PA6/PP/OMMT nanocomposites [4]. After introduction of PP-g-MA into PA6/PP/OMMT, the diffraction peak of OMMT disappears in the XRD pattern of PA6/PP/OMMT/ PP-g-MA nanocomposite. The absence of diffrac-

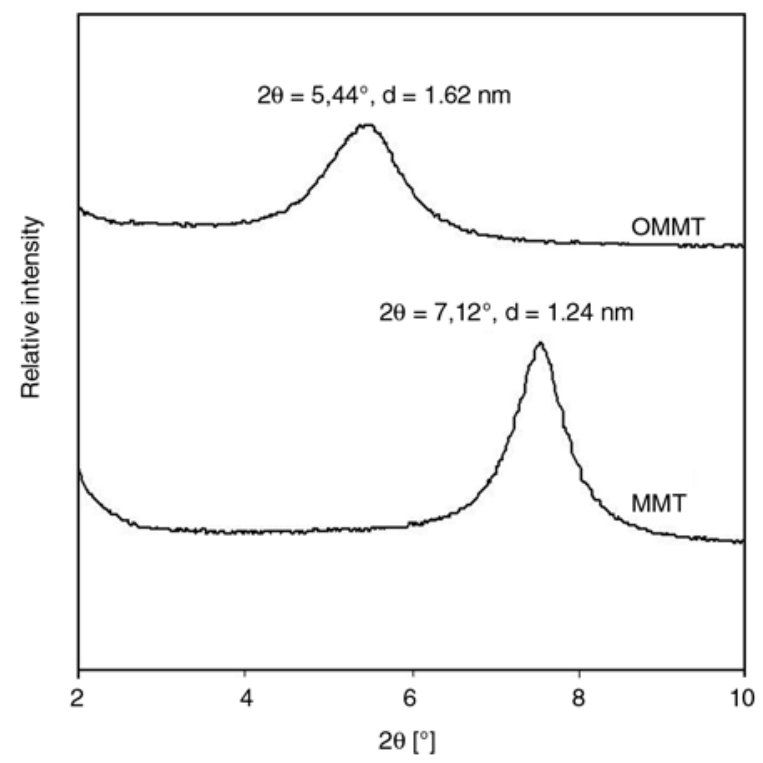

Figure 2. XRD patterns of MMT and OMMT

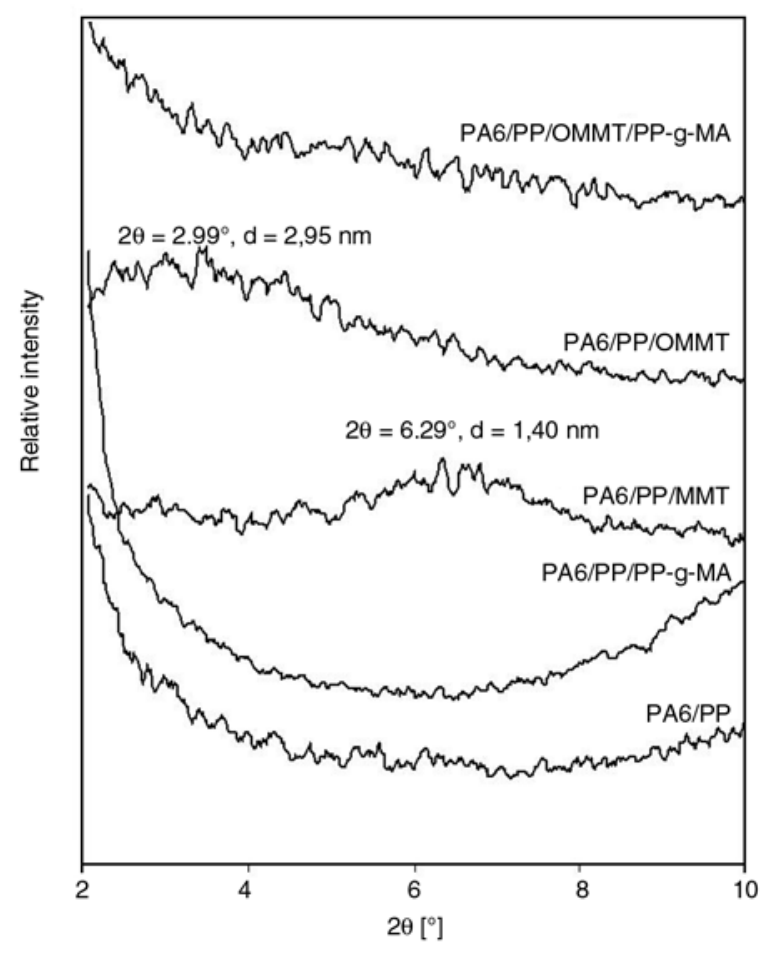

Figure 3. XRD patterns of PA6/PP blends and its nanocomposites

tion peak indicates the formation of exfoliated structure in the nanocomposite [4]. Thus, the presence of PP-g-MA in the PA6/PP/OMMT has promoted the dispersion and exfoliation of OMMT in the PA6/PP matrix. This may be attributed to the strong hydrogen-bonding interaction between maleic anhydride group in PP-g-MA and amine group in organic modifier of organoclay. This leads the expansion of interlayer spacing and further weakening of the interaction between the silicate layers. Furthermore, it will facilitate the intercalation of polymer matrix chains into the silicate galleries and results in the formation of the exfoliated structure [12].

\subsection{TEM}

Figures 4-6 display the TEM images of PA6/PP/ MMT, PA6/PP/OMMT, and PA6/PP/OMMT/PPg-MA nanocomposites, respectively. The dark lines represent the intersection of silicate layers whereas the gray background corresponds to PA6 phase. A poor dispersion of clay platelets, i.e. intercalated clay layers stacks and large clay aggregates can be observed in the TEM image of PA6/PP/MMT composite (cf. Figure 4). This may be attributed to the presence of strong electrostatic forces between clay layers [6]. The most exfoliated silicate layers and 


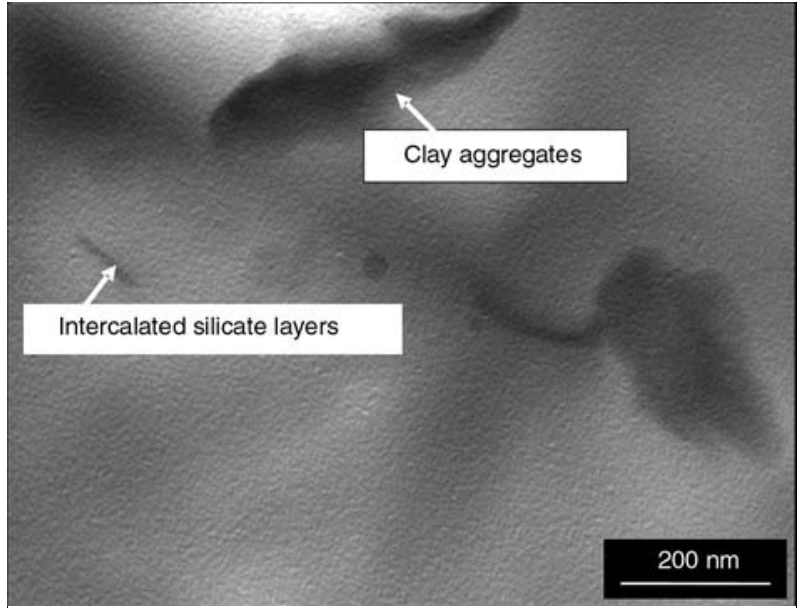

Figure 4. TEM image of PA6/PP/MMT composite

few intercalated clay layers stacks are observed in the PA6/PP/OMMT nanocomposite (cf. Figure 5). This suggests the formation of a mixture of intercalated and exfoliated structures in the nanocomposite. For PA6/PP/OMMT/PP-g-MA nanocomposite (cf. Figure 6), the individual silicate layers are homogenously dispersed in the PA6 phase, hence suggesting the formation of exfoliated structure. Accordingly, the presence of PP-g-MA in the PA6/PP/OMMT nanocomposite promoted the dispersion and exfoliation of silicate layers in the PA6 phase. When PA6/PP matrix, OMMT, and PP-gMA were mixed together, PP-g-MA could easily penetrate the interlayer of organoclay. The driving force for intercalation originates from the strong hydrogen bonding between maleic anhydride groups in PP-g-MA and amine groups in organoclay and leads to the expansion of interlayer spacing and a further weakening of interactions between the silicate layers [12]. This facilitates the intercalation of PA6 chains into silicate galleries

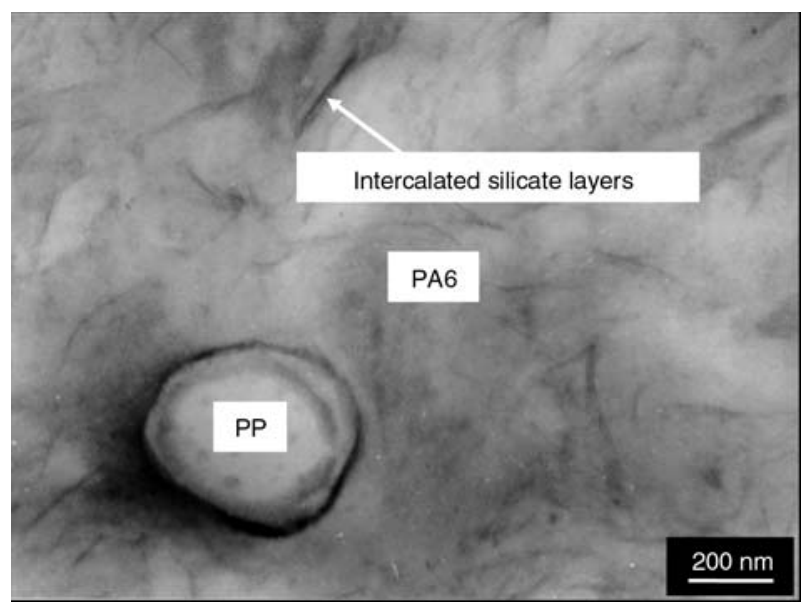

Figure 5. TEM image of PA6/PP/OMMT nanocomposite

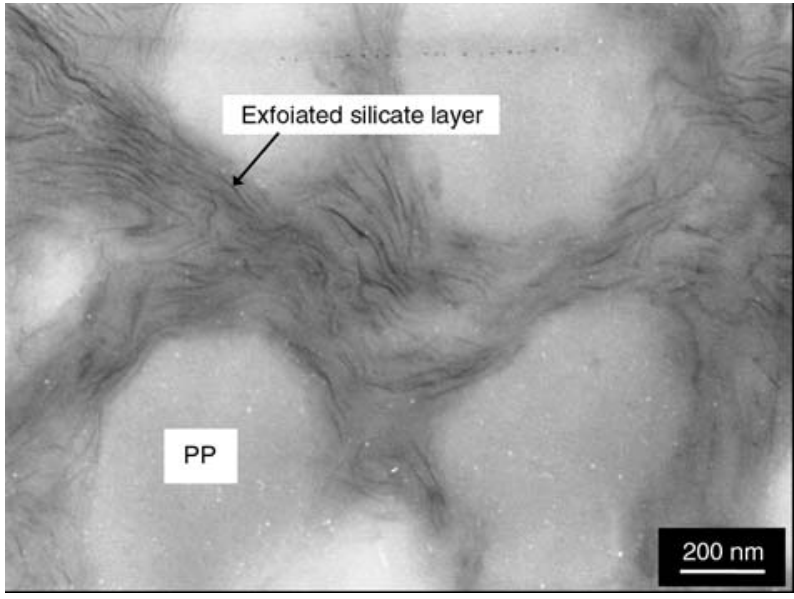

Figure 6. TEM image of PA6/PP/OMMT/PP-g-MA nanocomposite

and resulted in the formation of the exfoliated structure as confirmed by XRD results earlier. The better dispersion obtained by the addition of compatibilizer was also found by Pegoretti et al. [13] for PE-g-MA compatibilized PE/clay nanocomposites. Furthermore, the white particle dispersed in the PA6 phase corresponds to the PP phase without silicate layers inside (cf. Figures 5 and 6). The strong tendency of silicate layers to be located in the PA6 phase could be attributed to the fact that the silicate layers has a higher affinity to the more polar PA6 phase instead of PP phase. This is in agreement with our previous works on nanocomposites based on PA6 matrix [14] and PA6/PP blend [15] whereby AFM was used to prove the affinity of nanoclays to PA6 phase.

\subsection{TGA}

Figure 7 shows the TGA curves of MMT and OMMT. Below $100^{\circ} \mathrm{C}$, MMT exhibits a relatively higher weight loss than OMMT corresponding to the removal of water from interlayer coordinated to $\mathrm{Na}^{+}$. At this temperature, the weight loss for OMMT is lower because of the organophilic properties of OMMT containing alkyl ammonium ions [12]. The weight loss observed at $100-600^{\circ} \mathrm{C}$ for MMT may be attributed to the decomposition of hydrogen-bonded water molecules and some of the $\mathrm{OH}$ group from tetrahedral sheets [16]. On other hand, the greater weight losses displayed by OMMT in this temperature range could be explained mainly by the decomposition of intercalated ammonium and partly by the adsorbed water 


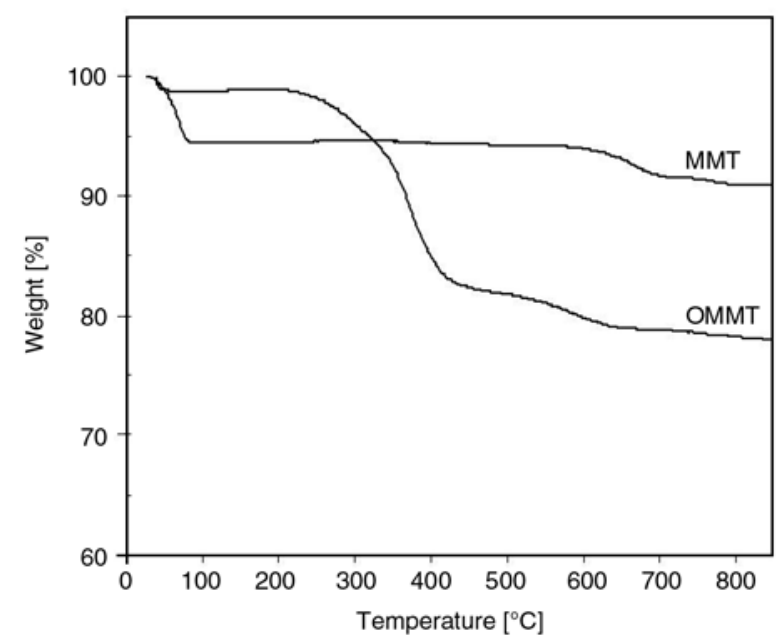

Figure 7. TGA curves of MMT and OMMT

molecules below $220^{\circ} \mathrm{C}$ [17]. In the temperature range of $600-850^{\circ} \mathrm{C}$, the weight losses for MMT and OMMT was probably associated with the dehydroxylation of MMT [18].

Figure 8 displays the TGA curves of PA6/PP blends and its nanocomposites. It can be seen that all samples displayed single-step degradation process. According to Liu et al. [19], the onset of decomposition temperature was characterized by the temperature at $5 \%$ weight loss $\left(T_{5 \%}\right)$ and summarized in Table 2. The decomposition of PA6/PP matrix started at $358^{\circ} \mathrm{C}$, whereas the onset of decomposition for PA6/PP/PP-g-MA was observed at $391^{\circ} \mathrm{C}$. This result indicates that the addition of PP-g-MA significantly improved the thermal stability of PA6/PP matrix. This could be attributed to the interaction (compatibility) between the maleic anhydride group of PP-g-MA and the amine termi-

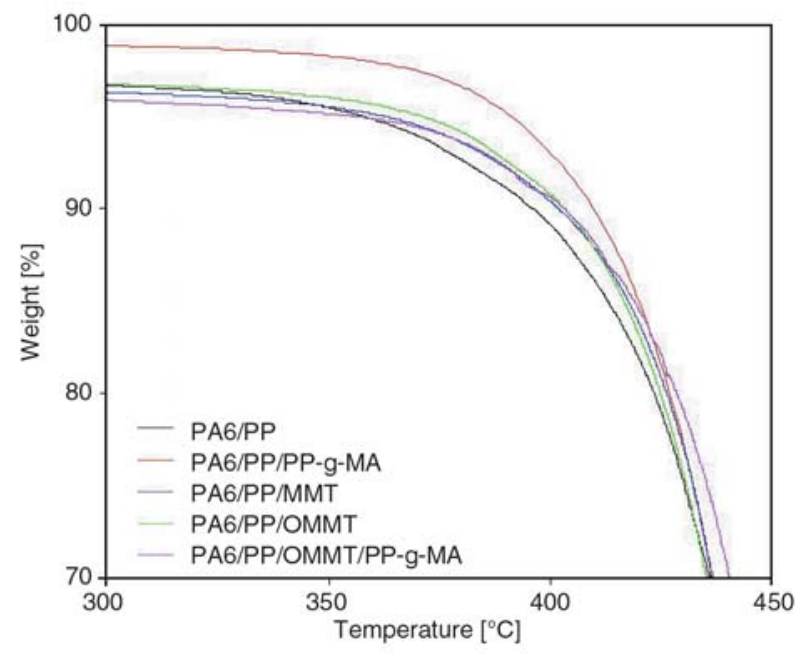

Figure 8. TGA curves of PA6/PP blends and its nanocomposites
Table 2. $T_{5 \%}$ and HDT of PA6/PP blends and its nanocomposites

\begin{tabular}{|l|c|c|}
\hline \multicolumn{1}{|c|}{ Sample designation } & T5\% $\left[{ }^{\circ} \mathbf{C}\right]$ & HDT $\left[{ }^{\circ} \mathbf{C}\right]$ \\
\hline PA6/PP & 358 & 90 \\
\hline PA6/PP/PP-g-MA & 391 & 92 \\
\hline PA6/PP/MMT & 362 & 98 \\
\hline PA6/PP/OMMT & 371 & 109 \\
\hline PA6/PP/OMMT/PP-g-MA & 355 & 113 \\
\hline
\end{tabular}

nal group of PA6 leading to the formation of a PPg-PA6 copolymer, which could act as a compatibilizer [20]. Furthermore, the onset of decomposition for PA6/PP/MMT and PA6/PP/OMMT was observed at 362 and $371{ }^{\circ} \mathrm{C}$, respectively. This indicates that the incorporation of both MMT and OMMT improved the thermal stability of PA6/PP matrix at the beginning of degradation stage. The improvement in the initial degradation temperature could be associated with the clay as an inorganic material with high thermal stability and great barrier properties that can prevent the heat from transmitting quickly and can limit the continuous decomposition [21]. Furthermore, the initial decomposition temperature of PA6/PP/OMMT nanocomposite decreased, i.e. $355^{\circ} \mathrm{C}$ in the presence of PP-gMA. The degradation of PP-g-MA is probably believed to be responsible for the observed trend. Furthermore, in the temperature range of 400 $500^{\circ} \mathrm{C}$, the PA6/PP/OMMT/PP-g-MA nanocomposite exhibited higher decomposition temperature than the PA6/PP blend and uncompatibilized PA6/PP/OMMT nanocomposites, indicating the enhancement of the thermal stability. The better dispersion and exfoliation of silicate layers in the polymer matrix for the PA6/PP/OMMT/PP-g-MA as confirmed by the XRD and TEM results earlier may be responsible for the improved thermal stability. The dispersed nanoscale silicate layers in the polymer matrix could be more effective in hindering diffusion of volatile decomposition products within the nanocomposite [22].

\subsection{HDT}

Table 2 summarizes the HDT of PA6/PP blends and its nanocomposites. It can be seen that HDT of PA6/PP blend slightly increased in the presence of PP-g-MA. Furthermore, the addition of both MMT and OMMT increased the HDT of PA6/PP blend. This confirms the improved thermal stability of the PA6/PP blend with the presence of clay particles. 
The presence of strong hydrogen bonds between the polymer matrix and clay surface is believed to be responsible for the increased HDT [23]. Compared with the PA6/PP/MMT composite, the PA6/ PP/OMMT nanocomposite exhibited better improvement in HDT due to the better dispersion and exfoliation of clay layers in the polymer matrix. Similar observations were reported by Mohanty and Nayak [22] and Xie et al. [23] for PA6/montmorillonite nanocomposites. They found that the exfoliated PA6/OMMT nanocomposites showed larger improvement in HDT as compared to the intercalated PA6/MMT nanocomposites. Furthermore, the slight increase in the HDT of PA6/PP/OMMT nanocomposite in the presence of PP-g-MA could be attributed to the compatibilization effect of PPg-MA.

\subsection{Mechanical properties}

Table 3 illustrates the tensile properties of the PA6/PP blends and its nanocomposites. It can be seen that the presence of PP-g-MA decreased the tensile modulus and strength of PA6/PP blend. The low modulus of PP-g-MA may be believed to be responsible for the observed trend. The addition of both MMT and OMMT significantly increased the tensile modulus of PA6/PP blend. This may be due to the reinforcement effect of the rigid inorganic clay and the constraining effect of silicate layers on molecular motion of polymer molecular chains [4, 6]. On other hand, the presence of both MMT and OMMT did not improve but decreased the tensile strength of PA6/PP blend. The poor dispersion of clay platelets as confirmed by the presence of a mixture of intercalated and exfoliated structures is believed to be responsible for the reduced tensile strength. It is interesting to note that the tensile modulus and strength of PA6/PP/OMMT significantly increased by the addition of PP-g-MA. By the addition of both OMMT and PP-g-MA, the ten- sile modulus and strength of PA6/PP matrix were increased by 27 and 30\%, respectively. This remarkable improvement could be attributed to the compatibilizing effect of PP-g-MA. The presence of PP-g-MA improved the interfacial adhesion between PA6, PP, and OMMT resulting from the formation of PP-g-PA6 copolymer; besides promoting dispersion and exfoliation of OMMT in the PA6/PP matrix as confirmed by XRD and TEM results discussed earlier. It is accepted that the hydrogen bonding could form between the amide group of the PP-g-PA6 copolymer and amine group of organic modifier in the OMMT. This amideamine reaction could happen when the OMMT was exfoliated in the PA6/PP matrix; subsequently the amine group of organic modifier is capable of forming a chemical linkage with PP-g-PA6 copolymer. The formation of PP-g-PA6 and the chemical linkage of PP-g-PA6 copolymer with organic modifier of OMMT have been reported in our previous study [24] for PP-g-MA compatibilized PA6/PP nanocomposites using commercial organoclay with the organic modifier of octadecylamine (Nanomer I30TC, USA). The tensile strength of PP-g-MA compatibilized PA6/PP nanocomposites containing OMMT with the organic modifier of dodecylamine (51.81 MPa) is higher than the commercial organoclay (49.6 MPa). This could be attributed to the OMMT containing dodecylamine is more effective for the formation of the exfoliated structure. Reichert et al. [8] have reported a similar observation where the presence of PP-g-MA enhanced the tensile modulus and strength of PP/organoclay nanocomposites due to the improved interfacial adhesion between PP and organoclay.

From Table 3, it is evident that the elongation at break of PA6/PP blend drastically increased with the presence of PP-g-MA. This could be attributed to the formation of PP-g-PA6 copolymer which improved interfacial adhesion between PA6 and PP phases. Furthermore, the addition of both MMT

Table 3. Mechanical properties of PA6/PP/OMMT nanocomposites

\begin{tabular}{|l|c|c|c|c|c|c|}
\hline \multicolumn{1}{|c|}{ Sample designation } & $\begin{array}{c}\text { Tensile } \\
\text { modulus } \\
{[\mathbf{G P a}]}\end{array}$ & $\begin{array}{c}\text { Tensile } \\
\text { strength } \\
{[\mathbf{M P a}]}\end{array}$ & $\begin{array}{c}\text { Elongation } \\
\text { at break } \\
{[\%]}\end{array}$ & $\begin{array}{c}\text { Flexural } \\
\text { modulus } \\
{[\mathbf{G P a}]}\end{array}$ & $\begin{array}{c}\text { Flexural } \\
\text { strength } \\
{[\mathbf{M P a}]}\end{array}$ & $\begin{array}{c}\text { Impact } \\
\text { strength } \\
{\left[\mathbf{k J} / \mathbf{m}^{2}\right]}\end{array}$ \\
\hline PA6/PP & $1.76 \pm 0.02$ & $39.96 \pm 0.43$ & $12.21 \pm 0.75$ & $1.91 \pm 0.05$ & $62.50 \pm 1.25$ & $5.47 \pm 0.45$ \\
\hline PA6/PP/PP-g-MA & $1.60 \pm 0.00$ & $30.70 \pm 1.80$ & $55.70 \pm 6.30$ & $1.70 \pm 0.00$ & $59.20 \pm 0.40$ & $6.10 \pm 0.40$ \\
\hline PA6/PP/MMT & $1.95 \pm 0.02$ & $38.65 \pm 0.82$ & $8.15 \pm 0.91$ & $2.32 \pm 0.05$ & $62.51 \pm 0.03$ & $3.58 \pm 0.18$ \\
\hline PA6/PP/OMMT & $2.01 \pm 0.03$ & $38.67 \pm 0.46$ & $2.72 \pm 0.14$ & $2.56 \pm 0.04$ & $62.22 \pm 0.42$ & $1.55 \pm 0.05$ \\
\hline PA6/PP/OMMT/PP-g-MA & $2.23 \pm 0.03$ & $51.81 \pm 0.88$ & $3.46 \pm 0.13$ & $2.56 \pm 0.03$ & $78.47 \pm 1.89$ & $1.88 \pm 0.11$ \\
\hline
\end{tabular}


and OMMT drastically decreased the elongation at break of PA6/PP matrix. This suggests that the PA6/PP matrix became brittle in the presence of clay particles. The reduction in ductility was attributed to the constrained mobility of polymer chains in the presence of clay particles [25]. The higher ductility observed for the PA6/PP/MMT compared to PA6/PP/OMMT nanocomposite may be attributed to the intercalated structure in the PA6/PP/ MMT composite and a mixture of intercalated and exfoliated structure in the PA6/PP/OMMT nanocomposite. Masenelli-Varlot et al. [26] reported that the intercalated PA6/clay nanocomposites had a higher elongation at break than exfoliated nanocomposites. The slight increase in elongation at break was obtained for the PP-g-MA compatibilized PA6/PP/OMMT nanocomposite albeit it was still lower than the PA6/PP blend. The improved interfacial adhesion between PA6, PP, and OMMT resulting from the formation of PP-g-PA6 a copolymer is believed to be responsible for the observed trend.

Table 3 also highlights the flexural properties of the PA6/PP blends and its nanocomposites. The addition of PP-g-MA reduced the flexural modulus and strength of PA6/PP blend. This trend resembles that of the tensile properties. The reduction in flexural properties could be attributed to the low molecular weight and low modulus of PP-g-MA. The incorporation of both MMT and OMMT significantly increased the flexural modulus of PA6/PP blend. This could be attributed to high stiffness and aspect ratio of silicate layers [27]. Compared with the PA6/PP/MMT composite, the flexural modulus of $\mathrm{PA} 6 / \mathrm{PP} / \mathrm{OMMT}$ nanocomposite was higher because of the nanoscale structure, the large aspect ratio, the large surface area of the layered silicates, and the corresponding strong interaction between polymer molecules chains and silicate surface [28]. On other hand, the flexural strength of PA6/PP matrix remained unchanged by the addition of both MMT and OMMT. However, the flexural properties of PA6/PP/OMMT nanocomposite significantly increased by the addition of PP-g-MA as in case of tensile properties discussed earlier. This may be again attributed to the compatibilizing effect of PPg-MA in which improved the interfacial adhesion and promoted the degree of exfoliation of OMMT in the PA6/PP matrix.
From Table 3, it can also be noted that the incorporation of PP-g-MA led to an increase in impact strength of the PA6/PP blend. A similar trend to that of the elongation at break was observed. The enhanced impact strength may be attributed to the improved interfacial adhesion between PA6 and PP resulting from the formation of PP-g-PA6 copolymer [3]. The incorporation of both MMT and OMMT drastically decreased the impact strength of PA6/PP blend. The reduction in toughness may be attributed to the lack of the crack front deflection and cavitation mechanisms in the clay-polymer nanocomposites reinforced with silicate nano-layers of high stiffness [29]. According to Nair et al. [30], the reduction in toughness of polyamide $6,6 /$ clay nanocomposites may be caused by the formation of micro voids or micro cracks in the crack-tip region and tend to reduce toughness. The lower impact strength observed for the PA6/PP/OMMT compared to the PA6/PP/MMT could be attributed to a mixture of intercalated and exfoliated structures in the nanocomposite. According to Miyagawa et al. [31], the individual exfoliated clay platelets ( 1 nm in thickness) are not effective to prevent the crack from propagating. It is easy to break the exfoliated clay platelets due to their high stiffness. Consequently, the PA6/PP/OMMT nanocomposite has low impact strength. Cavitation may occur in the vicinity of intercalated clay platelets in the PA6/PP/MMT composite. Cavitation mechanism may be believed to be responsible for higher impact strength in the PA6/PP/MMT [32]. Furthermore, the slight increase in impact strength could be observed for the PA6/PP/OMMT in the presence of PP-g-MA. The improved interfacial adhesion resulting from the formation of a PP-g-PA6 copolymer is believed to be responsible for the slight increase in toughness. The improvement in impact strength by the addition of PP-g-MA was also reported by Liu et al. [33] for PA6/clay nanocomposites.

\section{Conclusions}

The organic modification of MMT with dodecylamine was successfully performed as confirmed by the FTIR (the presence of organic groups such as $-\mathrm{NH}$ and $-\mathrm{CH}$ ) and $\mathrm{XRD}$ results (the expanded basal spacing). XRD and TEM results revealed that the intercalated structure was formed for PA6/PP/ 
MMT composite, a mixture of intercalated and exfoliated structures for PA6/PP/OMMT nanocomposite, and exfoliated structure for PP-g-MA compatibilized PA6/PP/OMMT nanocomposite. The addition of both MMT and OMMT improved stiffness, thermal stability, and HDT but reduced toughness of PA6/PP matrix. The presence of PP-g-MA in the PA6/PP/OMMT nanocomposite enhanced properties such as stiffness, strength, ductility, impact strength, and HDT.

\section{Acknowledgements}

The authors would like to AUN/SEED-Net JICA, Japan for financial support (project grant no: 6050071) and shortterm study program for one of us (Mr. Kusmono) at Toyohashi University of Technology, Japan.

\section{References}

[1] Marco C., Ellis G., Gómez M. A., Fatou J. G., Arribas J. M., Campoy I., Fontecha A.: Rheological properties, crystallization, and morphology of compatibilized blends of isotactic polypropylene and polyamide. Journal of Applied Polymer Science, 65, 26652677 (1997)

[2] Ide F., Hasegawa A.: Studies on polymer blend of nylon and polypropylene or nylon 6 and polystyrene using the reaction of polymer. Journal of Applied Polymer Science, 18, 963-974 (1974).

[3] Sathe S. N., Devi S., Rao G. S. S., Rao K. V.: Relationship between morphology and mechanical properties of binary and compatibilized ternary blends of polypropylene and nylon 6. Journal of Applied Polymer Science, 61, 97-107 (1996).

[4] Liu T., Tjiu W. C., He C., Na S. S., Chung T. S.: A processing-induced clay dispersion and its effect on the structure and properties of polyamide 6. Polymer International, 53, 392-399 (2004).

[5] Cho J. W., Paul D. R.: Nylon 6 nanocomposites by melt compounding. Polymer, 42, 1083-1094 (2001).

[6] Yu Z. Z., Yan C., Yang M., Mai Y. W.: Mechanical and dynamic mechanical properties of nylon 66/montmorillonite nanocomposites fabricated by melt compounding. Polymer International, 53, 1093-1098 (2004).

[7] Ma C. C. M., Kuo C. T., Kuan H. C., Chiang C. L.: Effects of swelling agents on the crystallization behavior and mechanical properties of polyamide 6/ clay nanocomposites. Journal of Applied Polymer Science, 88, 1686-1693 (2003).
[8] Reichert P., Nitz H., Klinke S., Brandsch R., Thomann R., Mülhaupt R.: Poly(propylene)/organoclay nanocomposite formation: Influence of compatibilizer functionality and organoclay modification. Macromolecular Materials and Engineering, 275, 8-17 (2000).

[9] Chow W. S., Mohd Ishak Z. A., Ishiaku U. S., KargerKocsis J., Apostolov A. A.: The Effect of organoclay on the mechanical properties and morphology of injection-molded polyamide 6/polypropylene nanocomposites. Journal of Applied Polymer Science, 91, 175-189 (2004).

[10] Tang Y., Hu Y., Zhang R., Gui Z., Wang Z., Chen Z., Fan W.: Investigation on polypropylene and polyamid-6 alloys/montmorillonite nanocomposites. Polymer, 45, 5317-5326 (2004).

[11] Agag T., Takeichi T.: Polybenzoxazine-montmorillonite hybrid nanocomposites: synthesis and characterization. Polymer, 41, 7083-7090 (2000).

[12] Zheng H., Zhang Y., Peng Z., Zhang Y.: Influence of the clay modification and compatibilizer on the structure and mechanical properties of ethylene-propylenediene rubber/montmorillonite composites. Journal of Applied Polymer Science, 92, 638-646 (2004).

[13] Pegoretti A., Dorigato A., Penati A.: Tensile mechanical response of polyethylene-clay nanocomposites. Express Polymer Letters, 1, 123-131 (2007).

[14] Chow W. S., Mohd Ishak Z. A.: Mechanical, morphological and rheological properties of polyamide 6/organo-montmorillonite nanocomposites. Express Polymer Letters, 1, 77-83 (2007).

[15] Chow W. S., Mohd Ishak Z. A., Karger-Kocsis J.: Atomic force microscopy study on blend morphology and clay dispersion in polyamide-6/polypropylene/ organoclay systems. Journal of Polymer Science Part B: Polymer Physics, 43, 1198-1204 (2005).

[16] Bray H. J., Redfern S. A. T., Clark S. M.: The kinetics of dehydration in Ca-montmorillonite; an in situ X-ray diffraction study. Mineralogical Magazine, 62, 647656 (1998).

[17] Bala P., Samantaraya B. K., Srivastava S. K.: Synthesis and characterization of Na-montmorillonite-alkylammonium intercalation compounds. Materials Research Bulletin, 35, 1717-1724 (2000).

[18] Olphen H. V., Fripiat J. J.: Data handbook for clay materials and other non-metallic minerals. Pergamon Press, Oxford (1979).

[19] Liu T., Lim K. P., Tjiu W. C., Pramoda K. P., Chen Z. K.: Preparation and characterization of nylon 11/organoclay nanocomposites. Polymer, 44, 3529 3535 (2003).

[20] Jose S., Thomas P. S., Thomas S., Karger-Kocsis J.: Thermal and crystallisation behaviours of blends of polyamide 12 with styrene-ethylene/butylene-styrene rubbers. Polymer, 47, 6328-6336 (2006). 
[21] Zhang W., Liang Y., Luo W., Fang Y.: Effects of claymodifying agents on the morphology and properties of poly (methyl methacrylate)/clay nanocomposites synthesized via $\gamma$-ray irradiation polymerization. Journal of Polymer Science Part A: Polymer Chemistry, 41, 3218-3226 (2003).

[22] Mohanty S., Nayak S. K.: Effect of clay exfoliation and organic modification on morphological, dynamic mechanical, and thermal behavior of melt-compounded polyamide- 6 nanocomposites. Polymer Composites, 28, 153-162 (2007).

[23] Xie S., Zhang S., Wang F., Liu H., Yang M.: Influence of annealing treatment on the heat distortion temperature of nylon-6/montmorillonite nanocomposites. Polymer Engineering and Science, 45, 1247-1253 (2005).

[24] Chow W. S., Mohd Ishak Z. A., Karger-Kocsis J., Apostolov A. A., Ishiaku U. S.: Compatibilizing effect of maleated polypropylene on the mechanical properties and morphology of injection molded polyamide 6/polypropylene/organoclay nanocomposites. Polymer, 44, 7427-7440 (2003).

[25] Chen L., Wong S. C., Pisharath S.: Fracture properties of nanoclay-filled polypropylene. Journal of Applied Polymer Science, 88, 3298-3305 (2003).

[26] Masenelli-Varlot K., Reynaud E., Vigier G., Varlet J.: Mechanical properties of clay reinforced polyamide. Journal of Polymer Science Part B: Polymer Physics, 40, 272-283 (2002).
[27] Parija S., Nayak S. K., Verma S. K., Tripathy S. S.: Studies on physico-mechanical properties and thermal characteristics of polypropylene/layered silicate nanocomposites. Polymer Composites, 25, 646-652 (2004).

[28] Shishan W., Dingjun J., Xiaodong O., Fen W., Jian S.: The structure and properties of PA6/MMT nanocomposites prepared by melt compounding. Polymer Engineering and Science, 44, 2070-2074 (2004).

[29] Bao S. P., Tjong S. C.: Impact essential work of fracture of polypropylene/montmorillonite nanocomposites toughened with SEBS- $g$-MA elastomer. Composites Part A: Applied Science and Manufacturing, 38, 378-387 (2007).

[30] Nair S. V., Goettler L. A., Lysek B. A.: Toughness of nanoscale and multiscale polyamide- 6,6 composites. Polymer Engineering and Science, 42, 1872-1882 (2002).

[31] Miyagawa H., Jurek R. J., Mohanty A. K., Misra M., Drzal L. T.: Biobased epoxy/clay nanocomposites as a new matrix for CRFP. Composites Part A: Applied Science and Manufacturing, 37, 54-62 (2006).

[32] Zhang H., Zhang Z., Yang J. L., Friedrich K.: Temperature dependence of crack initiation fracture toughness of various nanoparticles filled polyamide 66 . Polymer, 47, 679-689 (2006).

[33] Liu X., Wu Q., Berglund L. A., Fan J., Qi Z.: Polyamide 6-clay nanocomposites/polypropylenegrafted-maleic anhydride alloys. Polymer, 42, 82358239 (2001). 